\title{
Element Stoichiometry, New Production and Nitrogen Fixation
}

\author{
Anthony F. Michaels \\ University of Southern California - Los Angeles, California USA
}

David M. Karl

University of Hawaii • Honolulu, Hawaii USA

\author{
Douglas G. Capone \\ University of Southern California - Los Angeles, California USA
}

\section{Introduction}

Over the decade and a half since planning for the Joint Global Ocean Flux Study (JGOFS) began, a number of shifts, both subtle and profound, have occurred in certain paradigms of biological and chemical oceanography. Nowhere have greater changes taken place than in the way we view the stoichiometry of elements in the ocean and the processes that influence these patterns. We started this era with a conception of new production that focused on nitrate, linked to other elements in a simple, generally stable ratio in the ocean. We now know that elemental ratios vary more than we thought. We also know far more about the importance of iron as a limiting nutrient and its effects on elemental stoichiometry. Assumptions about systems in steady state have given way to the recognition that nothing is constant except change. Relationships between nutrient fluxes and climate conditions over a broad spectrum of time scales have become apparent.

These changes in our perceptions accord biological processes a more significant role in the exchange of carbon between oceanic and atmospheric pools and open the door to the evaluation of possible options for the active sequestration of carbon dioxide $\left(\mathrm{CO}_{2}\right)$. They also provide a springboard for research in the post-JGOFS era that can elucidate these processes and predict their role in the future behavior of ocean ecosystems and elemental cycles.

Marine nitrogen and phosphorus cycles are inextricably linked to the carbon cycle in the ocean. Pioneering research efforts by Hildebrand W. Harvey, L.H.N. Cooper and Alfred C. Redfield established a robust quantitative ratio of carbon to nitrogen to phosphorus (C:N:P) in the cells of phytoplankton and particulate matter in the laboratory and in both surface and deep ocean waters. It became known as the
"Redfield Ratio," specifying 106 moles C to 16 moles N to 1 mole P. The observed biochemical, molecular and enzymatic similarities of most planktonic organisms led Redfield and his colleagues to a unifying theory that, while it has greatly simplified efforts to model the complex dynamics of nutrient fluxes in the sea, may have inadvertently stifled the examination and explanation of non-conforming evidence.

The Geochemical Ocean Sections (GEOSECS) field program in the 1970s produced the first high-quality global data on nutrient and transient tracer distributions. Analysis of these data sets confirmed the global distribution of relatively constant nutrient ratios. Although absolute ratios often varied from the canonical Redfield values, changes in nutrient levels along isopycnal or neutral density surfaces in the deep sea usually retained ratios near those specified by Redfield (Anderson and Sarmiento, 1994). Because of the apparent consistency of the Redfield ratio throughout the ocean, knowledge of one element allowed investigators to calculate the concentration of other elements, and by inference, the processes that controlled them.

Another paradigm that governed ways of thinking about nutrient fluxes when JGOFS began was the "new production hypothesis." Introduced by Dugdale and Goering (1967), this formulation distinguished between the recycling of a limiting nutrient within a system and its introduction from outside the system. For nitrogen in the euphotic zone, this approach was used to distinguish between the recycling of ammonium and the uptake of nitrate, introduced through upwelling from deep waters (Figure 1a). Eppley and Peterson (1979) extended this conceptual analysis to show the balance between imports and exports in a steady-state ocean and to begin to identify regional patterns in the pro- 
(a)

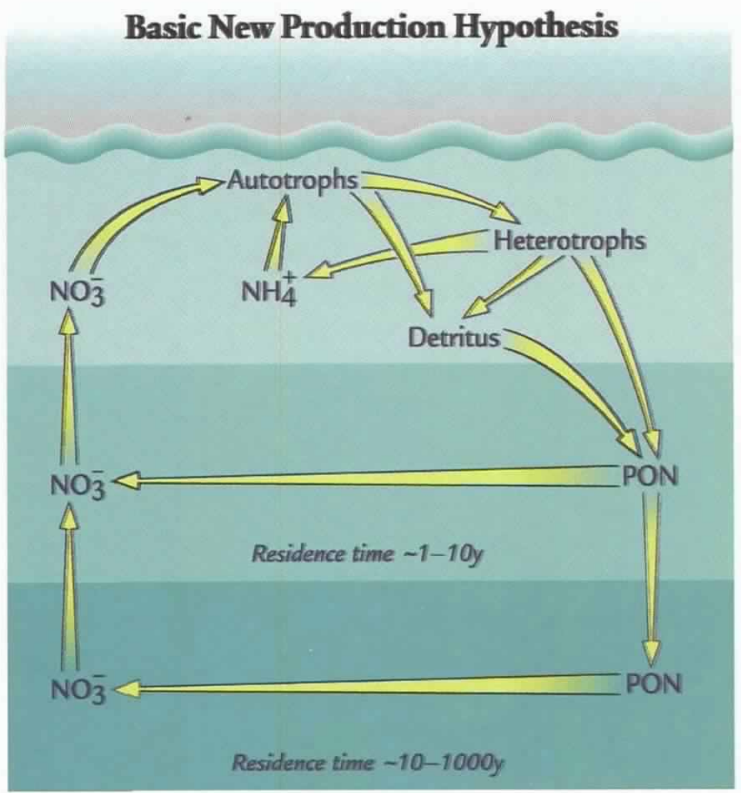

(c)

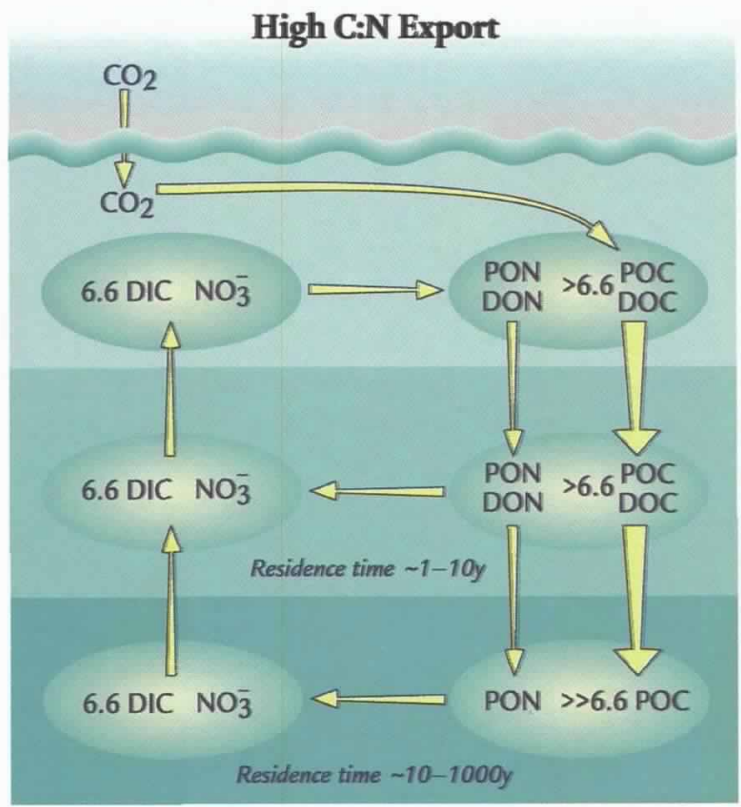

(b)

Fixed Redfield Ratio

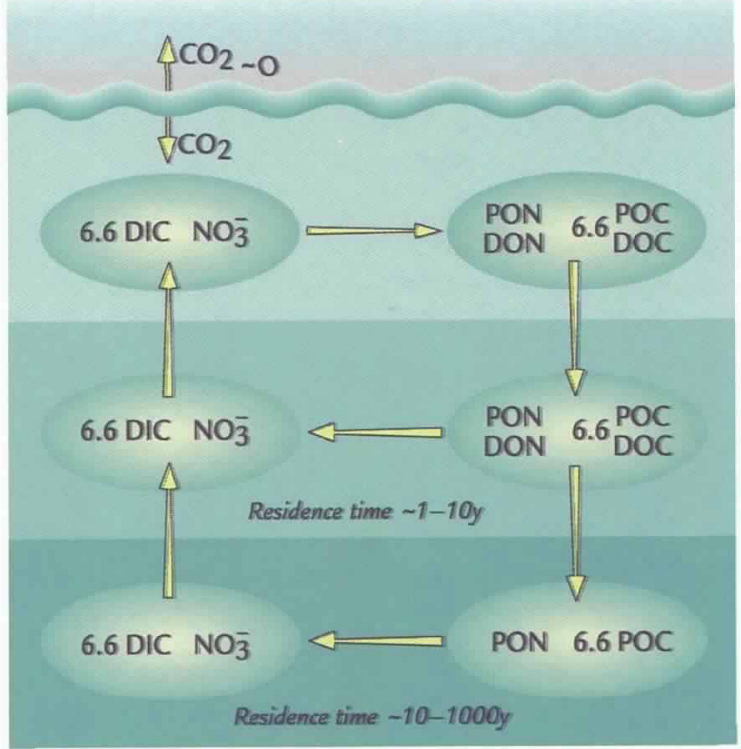

(d)

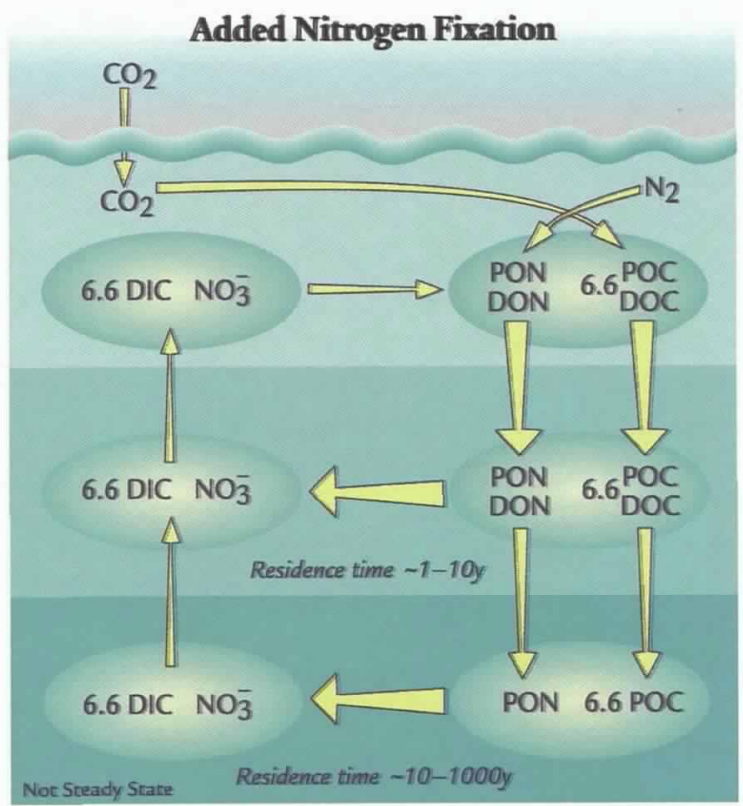

Figure 1. Coupling between the carbon and nitrogen cycles in the upper ocean. a) A simplified version of the "new production hypothesis." It compares growth based on exogenous "new" nutrients that enter the euphotic zone from above or below with that based on "regenerated" nutrients supplied by respiration within the euphotic zone. $\boldsymbol{b}$ ) Conceptual figure of the linkage between the nitrogen and carbon cycles under the assumption of a fixed C:N ratio of 6.6 moles:1 mole. c) A modified version of the coupled carbon and nitrogen cycles to illustrate the effect on $\mathrm{CO}_{2}$ uptake in the ocean of elevated C:N ratios in sinking particles or preferential loss of nitrogen during remineralization. In this model, the nitrogen cycle can remain at a steady state, but the carbon can build up in the deep sea on time scales shorter than the ventilation of the ocean. d) A modified version of the coupled carbon and nitrogen cycles to illustrate the effect of nitrogen fixation on the air-sea exchange of $\mathrm{CO}_{2}$. Increases in nitrogen fixation increase the total nitrate stock of the sea and the vertical gradient of $\mathrm{CO}_{2}$ as well as maintaining a lower surface $p \mathrm{CO}_{2}$. This system is not at steady state for either carbon or nitrogen. Increases in denitrification have an opposite effect, leading to net outgassing as the water returns to the surface with less nitrate, thus maintaining a weaker vertical gradient of $\mathrm{CO}_{2}$. 
portion of the total production that is based on exogenous nitrogen. Both articles mentioned the fixation of atmospheric nitrogen $\left(\mathrm{N}_{2}\right)$ and atmospheric deposition as sources of nitrogen for the upper ocean but, in line with the understanding at the time, treated them as negligible components of the exogenous flux that could be ignored in most first-order analyses.

\section{Contributions From JGOFS}

The discovery of elemental stoichiometry in the ocean that does not conform to the Redfield ratio was an unexpected consequence of the interdisciplinary and collaborative research fostered by JGOFS and other ocean programs such as the World Ocean Circulation Experiment (WOCE). In 1988, U.S. JGOFS established time-series programs in the subtropical gyres of the North Atlantic and the North Pacific with stations located near Bermuda and Hawaii respectively (see Karl et al., this issue). Repeated observations at the Bermuda-Atlantic Time-series Study (BATS) and Hawaii Ocean Time-series (HOT) sites over more than a decade have yielded recurrent, unexpected patterns that cannot be ignored as "one-off" anomalies but have to be considered as results of a basic set of processes that unfold through time.

During the first of the JGOFS process studies, the North Atlantic Bloom Experiment of 1989, key questions about element ratios were raised as investigators observed that the draw-down of inorganic nutrients during bloom conditions did not appear to obey the biogeochemical "rules" (Sambrotto et al., 1993). Carbon continued to disappear after the major nutrients were gone. At that time, the importance of dissolved organic phosphorus, nitrogen and carbon was not yet appreciated as the relevant analytical methods had just begun to be refined (see Hansell and Carlson, this issue). Thus uncertainties could still be regarded as associated with the unmeasured pool of dissolved organic matter (DOM) or ascribed to short time-scale measurements or horizontal processes unresolved by the sampling program.

Sediment trap measurements also raised questions about elemental stoichiometries. Nitrogen appeared to be remineralized over shallower depths than carbon (Martin et al., 1987). This observation made sense as the relative lability of these two elements is influenced by the biological needs of heterotrophic communities in deeper waters. The cells of bacteria and protozoa contain more nitrogen and phosphorus than the sinking detritus does. The difference in elemental composition suggests that these organisms work harder to mobilize and assimilate nutrients than they do carbon. However, this fractionation cannot be sustained if elements are constantly remineralized in mid-water in accordance with the Redfield ratio, a pattern clearly shown in most deep ocean waters.

Data from the first five years of measurements at the U.S. JGOFS time-series sites near Hawaii and Bermuda expanded the scale of questions about ele- ment ratios and required the formulation of hypotheses to explain anomalies that occurred year after year or showed a consistent trend over time. The time-series stations were also the first sites at which a wide variety of measurements were made in the same place and over the same time periods. They also attracted investigators from a variety of disciplines, increasing the opportunity to explore novel solutions.

In the Bermuda study, anomalous patterns showed up both in the elemental ratios observed and in efforts to use mass-balance approaches to understand the overall carbon cycle of the region (Michaels et al., 1994). Bermuda, located in the Sargasso Sea, is far enough north that the seasonal cycle involves relatively deep winter mixing followed by stratification in summer and fall. Each year this seasonal cycle homogenizes carbon and other nutrients in the upper ocean. Following the late spring stratification, biological and physical processes create vertical gradients in nutrients and carbon. Winter mixing introduces nitrate into the surface ocean that is quickly removed through primary productivity and export. However, the total dissolved inorganic carbon (DIC) continues to decline throughout the late spring and summer in the absence of new nitrate (Figure 2).

Were nitrate to be added by mixing through eddies or other processes, additional DIC would be introduced as well. Thus simple enhancements of the nitrate-driven new production cannot produce the observed results. Patterns in the concentrations of dissolved organic matter (DOM) and gas exchange also cannot explain the loss of DIC (Michaels et al., 1994). Results from regional cruises show that horizontal advection is unlikely to cause the continued decline of DIC each summer; the gradients are small and the seasonal pattern widespread. Where is this carbon going, how and why?

The Sargasso Sea is characterized by another nutrient anomaly as well. Ratios of nitrate to phosphate in the upper $1000 \mathrm{~m}$ of this basin are much higher than in most other parts of the ocean, even when corrected for asymmetries resulting from analytical errors at low concentrations. This implies either that the remineralization of nitrate occurs much faster than that of phosphate, the opposite of what one would expect from the relative lability of the nutrients, or that export from the euphotic zone includes more nitrogen than the Redfield ratio predicts. Further, the transition from a well-mixed layer $250 \mathrm{~m}$ deep in the spring to a stratified water column in the fall is accompanied by gradients in DIC and nutrients over this depth range, the result of productivity in the surface waters and remineralization below. The remineralization ratio of $\mathrm{C}: \mathrm{N}: \mathrm{P}$ that results from a comparison of these gradients is approximately 377:24:1, very different from the Redfield ratio (Table 1).

The ratio of nitrate to phosphate can be reformulated as a nitrate anomaly, often referred to as $\mathrm{N}^{*}$ (Michaels et al., 1996; Gruber and Sarmiento, 1997), by subtracting a scaled phosphate concentration from the 

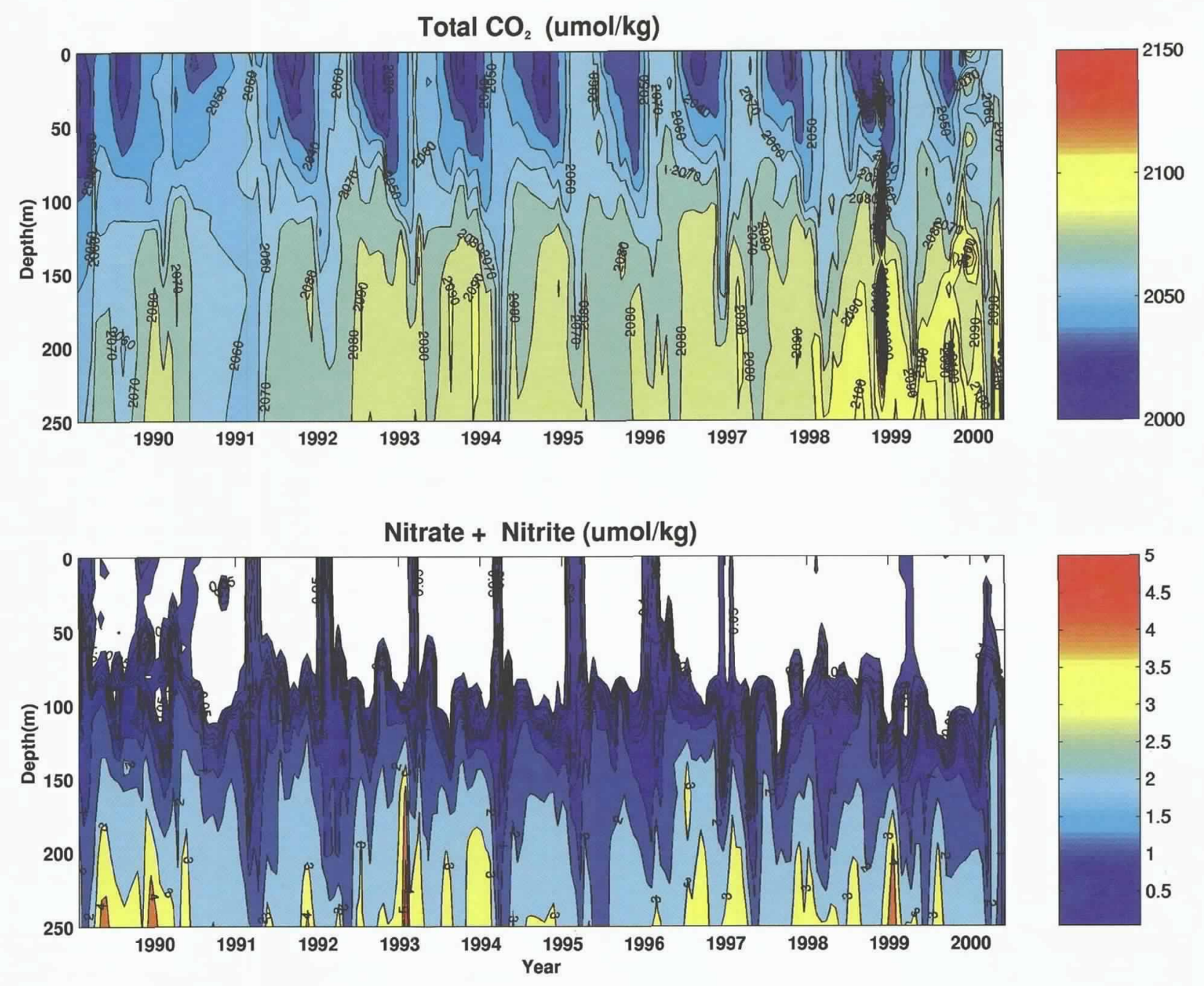

Figure 2. Decadal patterns of dissolved inorganic carbon (DIC) and nitrate at the Bermuda Atlantic Time-series Study (BATS). DIC in the upper $100 \mathrm{~m}$ declines steadily through the summer while the nitrate, briefly present in the early spring, is generally absent the rest of the year. Dissolved organic carbon (not shown here) also declines or changes little through the summer (Michaels et al., 1994).

measured nitrate value $\left(\mathrm{NO}_{3}-16 * \mathrm{PO}_{4}\right.$ or some variant thereof). $\mathrm{N}^{*}$ will be higher when high $\mathrm{N}: \mathrm{P}$ organic matter is exported and subsequently remineralized or when nitrogen is preferentially remineralized from exported dissolved and particulate organic matter. The current balance of evidence indicates that $\mathrm{N}_{2}$ fixation in surface waters can be a source of high N:P organic matter. $\mathrm{N}^{*}$ will be lower when nitrate is removed in denitrification or when phosphate is preferentially remineralized from exported dissolved and particulate organic matter. In the Sargasso Sea, $\mathrm{N}^{*}$ data can be used to infer the rate of creation of the excess nitrate. Values for the region range from 28 to $90 \mathrm{Tg} \mathrm{N} / \mathrm{y}\left(\mathrm{Tg}=10_{12}\right.$ grams), dramatically higher than previous estimates of oceanic nitrogen fixation worldwide (Michaels et al., 1996, Gruber and Sarmiento, 1997).

Gruber and Sarmiento (1997) applied the $\mathrm{N}^{*}$ approach on the global scale and concluded that the patterns of positive and negative $\mathrm{N}^{*}$ are associated with the balance between denitrification and this putative nitrogen fixation. Strong cross-basin patterns of $\mathrm{N}^{*}$ suggest the creation of nitrate in the surface waters of the gyres and the loss of nitrate in the well-developed oxygen minima under the equatorial and eastern boundary current upwelling zones. The spatial correspondence between strong positive $\mathrm{N}^{*}$ anomalies and aeolian dust flux is particularly striking (Figure 3 ). Both the data from the Sargasso Sea and the global analyses suggest that iron in these aeolian dust inputs may serve as a control on nitrogen fixation, an hypothesis that requires further research.

At the Hawaii Ocean Time-series (HOT) station, investigators with a more biological orientation came to similar conclusions about $\mathrm{N}_{2}$ fixation and further 


\section{Table 1}

Comparison of the mean concentration of inorganic carbon, nitrate and phosphate in upper $100 \mathrm{~m}$ with that between 150 and $250 \mathrm{~m}$. Data from the Bermuda Altantic Time-Series Station in the September-October period when mixed-layer depths are still less than $100 \mathrm{~m}$. If we assume that the spring mixing to $250 \mathrm{~m}$ homogenizes the water column, the fall comparison may indicate net remineralization stoichiometries from the previous summer.

\begin{tabular}{lccc} 
& DIC & Nitrate & Phosphate \\
\hline $0-100$ m mean $(\mu M)$ & 2043 & 0.08 & 0.02 \\
$150-250$ m mean $(\mu \mathrm{M})$ & 2084 & 2.67 & 0.13 \\
Difference $(\mu \mathrm{M})$ & 41 & 2.59 & 0.11
\end{tabular}

D DIC: D Nitrate $=15.9$ (mole $/ \mathrm{mole})$

D DIC: D Phosphate $=377(\mathrm{~mole} / \mathrm{mole})$

D Nitrate: D Phosphate $=23.6(\mathrm{~mole} / \mathrm{mole})$

redefined our sense of the instability of ocean nutrient stoichiometry over time. Several lines of evidence from HOT Station ALOHA, located at $22^{\circ} 45^{\prime} \mathrm{N}, 158^{\circ} \mathrm{W}$, suggest that $\mathrm{N}_{2}$ fixation has been an important source of new nitrogen for the pelagic ecosystem of the North Pacific subtropical gyre since the early 1990s. The evidence includes measurements of the abundance of Trichodesmium, cyanobacteria species that fix $\mathrm{N}_{2}$ in the open ocean, and estimates of the potential rate at which $\mathrm{N}_{2}$ fixation takes place; assessment of the molar $\mathrm{N}: \mathrm{P}$ stoichiometries of surface-ocean dissolved and particulate matter pools and development of a onedimensional model to calculate mass balances for nitrogen and phosphorus; measurements of seasonal variations in the natural abundance of ${ }^{15} \mathrm{~N}$, an isotope of nitrogen, in particulate matter exported to the deep sea, and observations of secular changes in soluble reactive phosphorus (SRP), soluble nonreactive phosphorus (SNP) and dissolved organic nitrogen (DON) pools during the period of increased rates of $\mathrm{N}_{2}$ fixation (Karl et al., 1997).

Budget estimates suggest that $\mathrm{N}_{2}$ fixation is currently supplying up to half of the nitrogen required to sustain the observed export of particulate matter from the euphotic zone at Station ALOHA. But observations also suggest that this relatively high level of $\mathrm{N}_{2}$-supported production may represent a transient state of the ecosystem. This state may be simply a phase in a long-term cycle, or it may represent a shift in response to well-documented decade-long changes in climate in the North Pacific (Karl et al., this issue). Our changing perspective on biogeochemical dynamics in the gyre is likely to have a profound influence on how we model ecosystem processes, including the potential effects of natural or anthropogenic environmental change and their relationship to carbon sequestration in the ocean.

Results from the two JGOFS time-series programs tell us that the ocean's major nutrient cycles are dynamic rather than static (Karl et al., this issue). They vary significantly on time scales ranging from diel to decadal and probably longer. Although measurements of $\mathrm{N}_{2}$ fixation were not explicitly part of the research program of the U.S. JGOFS regional process studies, results from the Arabian Sea Process Study show that, even in systems dominated by seasonal upwelling of nutrients, dense populations and spatially extensive surface blooms of Trichodesmium can occur throughout the central basin and do contribute directly and substantially to the nitrogen budget (Capone et al., 1998).

\section{Should We Be Surprised?}

Some would argue that the discovery of anomalous stoichiometries and the reassessment of the significance of $\mathrm{N}_{2}$ fixation as a source of nitrogen in ocean systems should not come as surprises. Geochemists have argued for years that $\mathrm{N}_{2}$ fixation should make up the deficit in ocean nitrogen budgets. Redfield himself observed in 1958 that "nitrogen fixation is so active that there is no difficulty in assuming that it might serve in adjusting the phosphorus-nitrogen ratio in the sea."

Certain fundamental limits on elemental composition in organisms are set by phosphate requirements for nucleotides, nucleic acids and membranes, the nitrogen requirements of proteins and varying iron requirements as a factor in specific enzymes of metabolism (Falkowski, 2000). However, there are many ways that organisms can make use of nutrient resources to grow and reproduce, even in the face of what appear at first to be exogenous limits. Thus some prokaryotic organisms can satisfy their need for one of the basic nutrients by fixing nitrogen from the nearly inexhaustible supply of dissolved $\mathrm{N}_{2}$ gas.

The biological literature is replete with studies that show large and flexible ranges in elemental stoichiometry for microorganisms growing under various light and nutrient regimes (Karl et al., 2001). The uptake of excess or "luxury" nutrients, especially phosphorus and iron, and the formation of carbon-rich storage products such 


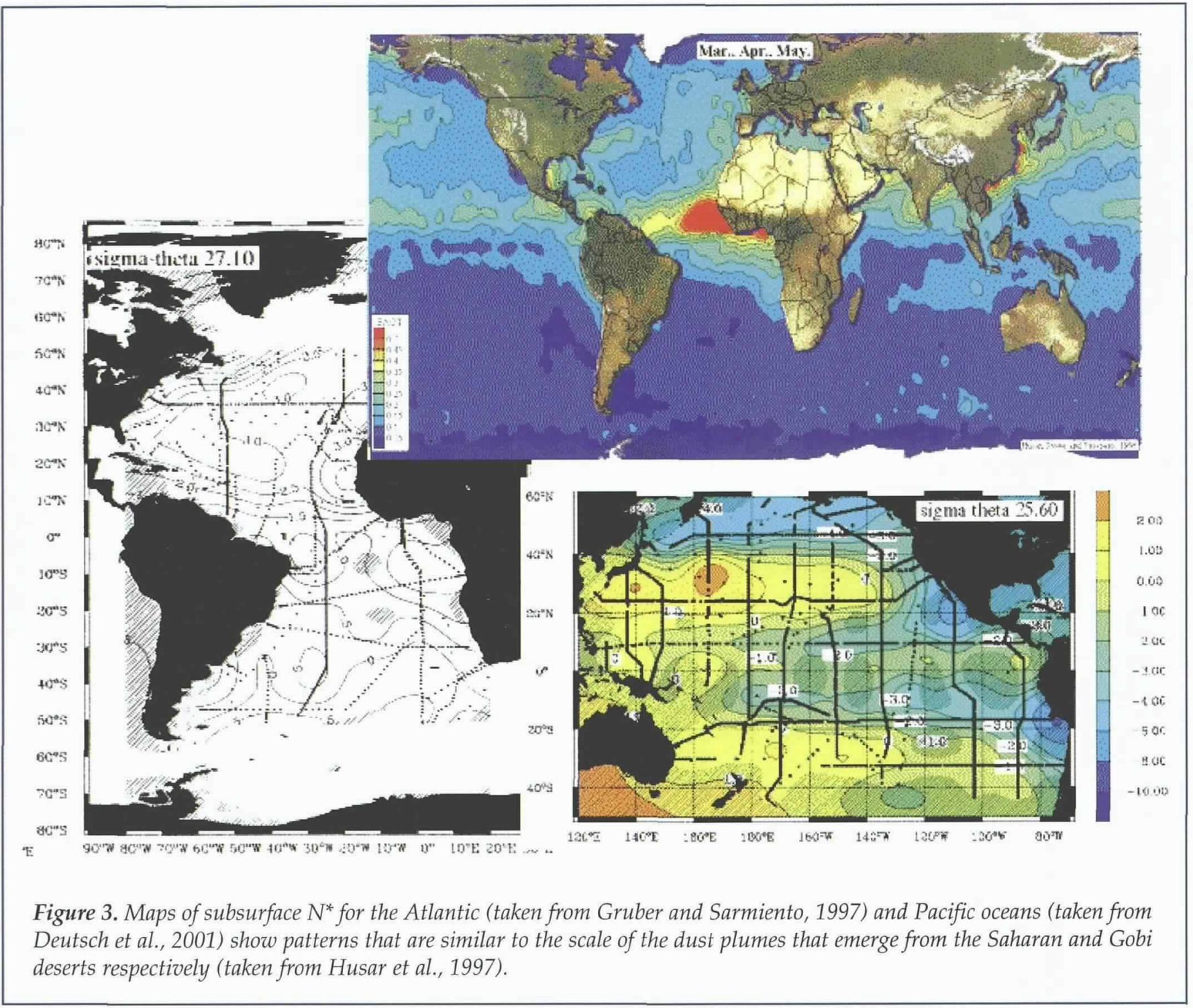

as lipids or polyhydroxybutyrate are commonplace in the microbial world. In freshwater systems, these organism-level processes yield a wide range of elemental ratios in the water or the ecosystem (Elser et al., 1996). No limnologist would accept the idea of a fixed and constant elemental stoichiometry in lakes. Perhaps our view of the ocean is affected by its enormous size and the long residence time of nutrients within it. But these facts should not constrain our thinking.

\section{Implications For Modeling The Ocean Carbon Cycle}

JGOFS is nearing the final stage of a synthesis and modeling effort to incorporate the discoveries of the field studies into a coherent set of predictive ocean carbon-cycle models. These models must, among other things, be able to describe current temporal and spatial patterns in the ocean uptake of $\mathrm{CO}_{2}$ and predict changes that might occur in the future. To do this, they must include all of the processes that can influence the partial pressure of $\mathrm{CO}_{2}\left(\mathrm{pCO}_{2}\right)$ in surface waters. Physical con- straints, such as the effects of temperature and wind speed on $\mathrm{pCO}_{2}$ and the exchange of gases across the airsea interface, have always been part of the thermodynamic calculations of these models. However, biological processes are less well understood and more difficult to describe. In the initial effort to incorporate biological and chemical processes into models of the carbon cycle, the Redfield ratio was a powerful tool for assessing the ability of the models to reproduce the basic biogeochemical patterns of the sea. When we turn to the need to predict oceanic responses to changing environmental conditions, we run up against its limitations.

The fixed stoichiometry of the Redfield ratio implies that nutrient uptake only removes a fixed amount of DIC from the surface water and that all of the carbon in the organic material formed is remineralized with the nutrients. Thus the introduction of nutrients into the surface ocean through upwelling brings with it sufficient DIC for the primary production that these nutrients fuel. Biological processes can contribute little net carbon sequestration in an ocean governed 
strictly by the Redfield ratio, regardless of the magnitude of the export flux or the size of the export ratio, unless changes occur in the High Nutrient-Low Chlorophyll (HNLC) areas where nutrients are underutilized (Figure 1b). A change in the rate of new production based on nitrate may affect the amount of material that is cycled, but it will have little effect on the DIC flux as long as nutrient removal is either complete or unchanging.

The assumption of a constant element ratio, when applied in the construction of a model, does not allow most biological processes any effect on the flux of carbon between atmosphere and ocean, except in systems where nutrients are not completely consumed. If this is how the ocean functions, we can ignore most biological processes and properties in creating our models. If, as we think, the stoichiometry of elements in the ocean is not always in line with that described by the Redfield ratio, then we have to understand the full implications of the different stoichiometries and include the appropriate processes in models in order to predict the effect of the living ocean on the flux of carbon between the ocean and the atmosphere.

If Redfield ratio assumptions are relaxed in a nonsteady-state world, the work of modeling carbon dynamics becomes more interesting (Figures $1 \mathrm{c}$ and 1d). The C:N ratio of exported materials is generally higher than the ratio of elements taken up in primary productivity. In this situation (Figure 1c), an increase in export flux causes a net transfer of carbon from the surface ocean to the deep sea on the time-scales involved in the ventilation of deep water masses (centuries to millennia). A decrease in export has the opposite effect. The same thing can occur if carbon is remineralized over a greater depth interval, on average, than nitrogen. On centennial to millennial time scales, the extra carbon in the deep sea will return to the surface. On interannual and decadal time scales, however, the uncoupling of the remineralization of nitrogen from the remineralization of carbon means that changes in the rates of biological processes, export in particular, can have a net effect on the atmospheric carbon concentration.

Another obvious modification of the fixed-ratio assumption that should be made is the inclusion of gas phases and the air-sea exchange of gases on the delivery side of the nitrogen cycle. Nitrogen is introduced into the ocean from the atmosphere, or from dissolved gases in the water that are ultimately equilibrated with the atmosphere, during deposition of nitrate and $\mathrm{N}_{2}$ fixation (Figure 1d). On a global scale, the deposition of reactive nitrogen plays a modest, though increasing role (Galloway et al., 1995), but oceanic $\mathrm{N}_{2}$ fixation appears to be more significant than previously thought (Capone, 2001).

The global rate of oceanic $\mathrm{N}_{2}$ fixation is now estimated to exceed 100-150 Tg N/y, and global denitrification rate estimates are even higher (Capone, 2001). On glacial-interglacial time scales, the balance of these processes changes the total amount of nitrate in the ocean within the permissible bounds set by the variability of N:P ratios in organisms. The balance of these two rates may also influence the sequestration of atmospheric $\mathrm{CO}_{2}$ in the ocean directly by providing new nitrogen to the upper ocean. Accumulating evidence indicates that iron availability may be one of the key factors regulating the growth of planktonic marine diazotrophs (organisms that fix $\mathrm{N}_{2}$ ) and thereby the relative amounts of $\mathrm{N}_{2}$ fixation versus denitrification. The primary pathway for the delivery of iron to the open ocean is through dust deposition.

Perhaps the most exciting implication of our improved understanding of the role of the diazotrophs is that $\mathrm{N}_{2}$ fixation may be directly involved in the global coupling between ocean biogeochemistry and the climate system. Consider the following set of linked hypotheses that emerge from this new understanding: The rate of $\mathrm{N}_{2}$ fixation in the global ocean may affect the concentration of $\mathrm{CO}_{2}$ in the atmosphere on time scales of decades (variability in surface biogeochemistry) to millennia (changes in the total stock of nitrate from the balance of $\mathrm{N}_{2}$ fixation and denitrification). Carbon dioxide concentrations in the atmosphere may influence climate. The climate system, in turn, may influence the rate of $\mathrm{N}_{2}$ fixation in the ocean by controlling the supply of iron in the form of dust derived from climatesensitive deserts ashore and by influencing the stratification of the upper ocean.

It is intriguing to speculate that the circular nature of these influences may constitute a feedback system, particularly on longer time-scales (Figure 4). Further, there are possible internal feedback dynamics within the ocean as changes in the total nitrate stock may, in turn, influence the rates of denitrification and $\mathrm{N}_{2}$ fixation. In addition, human activity may have a role in the current manifestation of this feedback cycle through agricultural practices on the margins of deserts that affect dust production as well as through the release of $\mathrm{CO}_{2}$ into the atmosphere from fossil fuel consumption and deforestation.

The key point is that the assumptions about simple and fully coupled nitrogen dynamics and rate processes in the upper ocean that arise from the traditional conceptualizations of element ratios and new production are not sufficient to explain what we observe or to predict change in ocean ecosystems. We need to understand how the deviations from our assumptions affect the links between elements. One of the most important lessons from the time-series programs and other JGOFS investigations is that intensive, long-term studies have revealed processes that are at odds with the assumptions based on our traditional paradigms. When we include newly examined pathways in our mental and numerical models, we conclude that air-sea carbon dynamics differ from the patterns indicated by these simplifying assumptions. Thus we have to look explicitly for these pathways to understand their effects. 


\title{
Modeling Biogeochemical cycles In The Post-JgOES Era
}

\author{
Raleigh R. Hood \\ University of Maryland Center for Environmental Science \\ Cambridge, Maryland USA
}

Modelers and field researchers alike have come to appreciate the importance of trace metals, silica and phosphorus in natural cycles as well as the evidence for elemental stoichiometry that varies from the relationships described by Alfred Redfield and his colleagues half a century ago. It is clear that if we want to model the more subtle aspects of elemental cycles in the ocean, which could be important in determining net carbon export on a variety of time scales, we will have to include multiple nutrients in our models and allow them to deviate from Redfield proportions. These realizations have emerged relatively recently, thanks in good part to measurements made at the Hawaii Ocean Time-series (HOT) and Bermuda Atlantic Timeseries Study (BATS) sites over the last decade (see Michaels et al., this issue; Karl et al., this issue).

The focus of most modeling studies since the early 1990s, however, has been on incorporating more realistic food-web structures into models. Examples include efforts at explicit representation of the microbial loop and multiple size classes of phytoplankton and zooplankton. This focus stems from the fact that food-web structure has a profound effect upon export of material from the euphotic zone. Considerable progress has been made, and numerous models now reproduce observed shifts in ecosystem structure and export flux in response to perturbations in nutrients and light.

With some level of success behind us, modelers are beginning to turn their attention to the role of multiple limiting nutrients and non-Redfield element cycling. Several recently developed regional and global models allow for multiple elements and differences in elemental composition among food-web components. But these models are becoming increasingly complicated, and we may have reached the limits of our ability to understand, validate and run them. Continued progress will require advances in our understanding of in situ elemental cycles and our ability to analyze and understand the dynamics of complicated model systems, as well as advances in computing power. At the same time we must avoid the temptation to build complicated "models of everything" that cannot be validated, have limited scientific usefulness and are nearly as difficult to understand as the systems we are trying to model.

The primary motivation for developing large-scale biogeochemical models is our hope of predicting how the ocean uptake of carbon dioxide will respond to anthropogenic perturbations and global warming. This is one scientific application where a "model of everything" is, perhaps, appropriate, because we seek to predict general and currently unknown biogeochemical responses to perturbations that may exceed anything we have observed before. However, there is no guarantee that complex models will be able to generate the correct ecosystem responses.

The truth is that we are "flying blind" in our efforts to predict the future with these models. Unlike our colleagues in physical oceanography, we have no underlying theoretical foundation to guide us. We do not have a complete system of equations that can be systematically studied and simplified for different applications with known limitations. One thing we do know is that a full set of equations capable of describing the functioning of biogeochemical cycles in the ocean is going to be incredibly complex.

The Redfield ratio provides one of the few general principles that we have. We know that, on average, the uptake and release of elements in the ocean tend to occur in specific proportions. The general explanatory power and robustness of the Redfield ratio suggests that it captures some fundamental aspect of elemental stoichiometry in ecosystems that is governed by physiological laws. The fact that models based upon the Redfield ratio fail to predict the details and subtleties of elemental cycles should come as no surprise. They fail because they do not include second- and third-order terms. The problem we face is that these terms are clearly important on short time and space scales, and they may be important when we integrate model results over longer time and space scales as well.

Perhaps biogeochemical models based upon the Redfield ratio are analogous to the geostrophic approximation in physics, and what we seek now is something more akin to primitive equations with multiple elements and variable stoichiometries. But the realization that elemental cycles in the ocean are often more complicated than a simple fixed ratio predicts in no way diminishes the Redfield ratio as an overarching principle in the study of biogeochemical cycles. Nor does it diminish its usefulness as a simplifying assumption in models, as long as the assumption is made with care. 


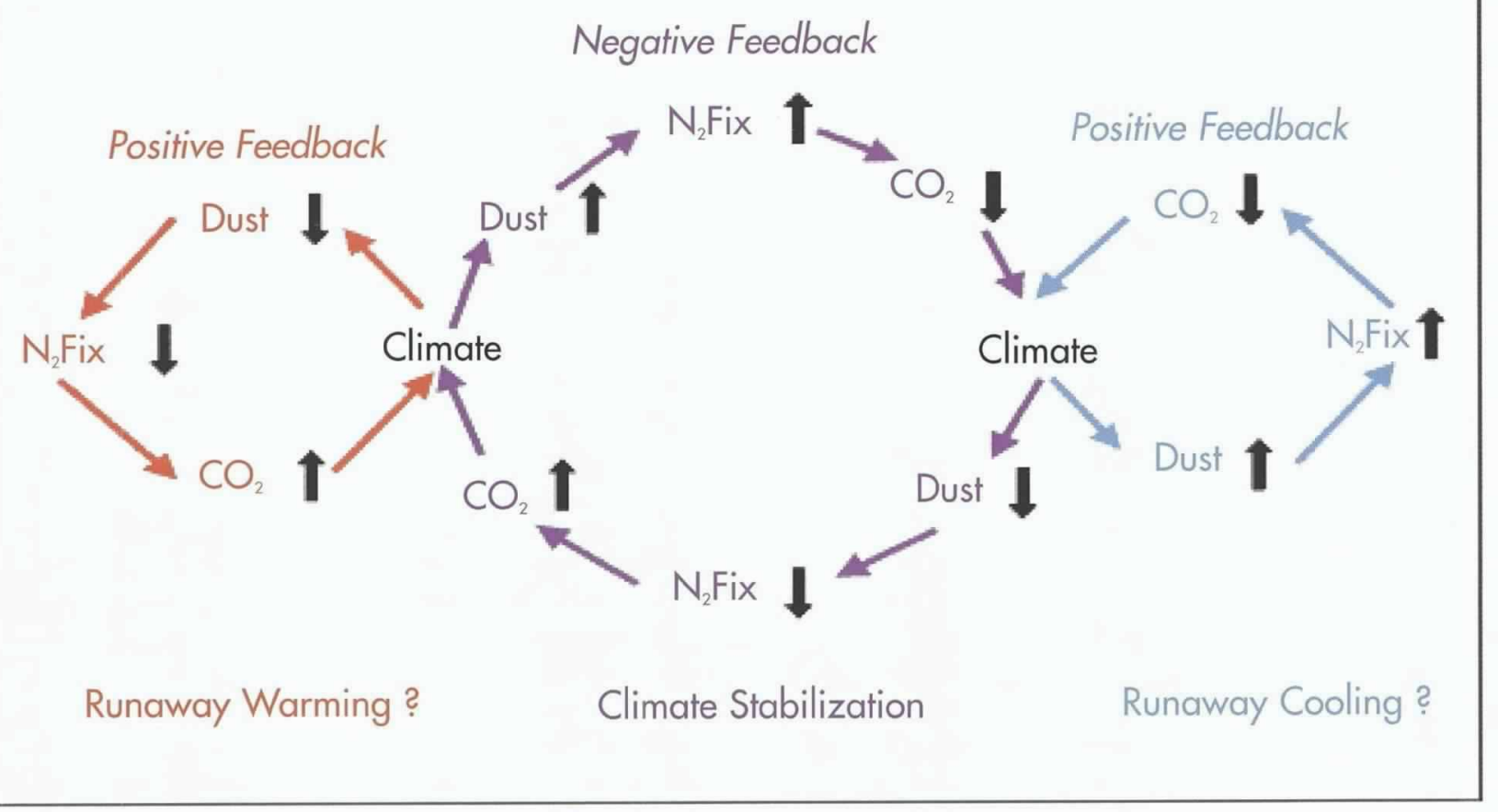

Figure 4. A hypothesis presented by the authors for a climate-based feedback cycle that involves nitrogen fixation, dust deposition and climate. The sign of the feedback is critically determined by the relationship between climate change and the supply of dust to the oligotrophic ocean gyres. If a warmer climate delivers more dust (and vice versa), then the cycle is stabilizing. If a warmer and perhaps wetter climate delivers less dust to a specific area, then the cycles could lead to runaway warming or cooling. The cycles are further bounded by the interaction of oceanic nitrate stocks on the rates of nitrogen fixation and denitrification, by the direct effects of climate on these rates and by the uncertain fate of iron in midwater.

\section{Conclusion}

In their treatise on nutrient dynamics in the sea, Dugdale and Goering (1967) were careful to emphasize that there were several potential sources of new nitrogen for the euphotic zone, each of equal value but with potentially different ecological consequences. As there were few data on $\mathrm{N}_{2}$ fixation rates when their original paper was published, importation of nitrate from below the euphotic zone was considered to provide most of the new nitrogen in the sea.

Thirty years after the new production concept was introduced, there is increasing evidence that rates of oceanic $\mathrm{N}_{2}$ fixation may have been systematically underestimated. More recently, application of modern molecular methods to detect the presence and composition of $\mathrm{N}_{2}$-fixing microorganisms at the U.S. JGOFS time-series sites has revealed a broad spectrum of previously uncharacterized gene sequences (Zehr et al., 2000). Yet-to-be-cultured microorganisms may hold the key to further understanding of carbon cycle dynamics (Capone, 2001).
We conclude that ecosystem models and biogeochemical extrapolations should be carefully reconsidered to determine the effects of traditional simplifying assumptions on their dynamics. The fact that the Redfield ratio paradigm has been with us so long, like the new versus recycled production conceptualization of nutrient dynamics, reflects our history of undersampling, a previously limited set of technical approaches and less than complete understanding of biological dynamics in the sea. It also reflects the power of early generalizations in structuring great advances in our field. The challenge is knowing when to use these simplifying assumptions and when to move on.

We submit that the time has come for a careful and complete reconsideration of the Redfield ratio and the new/export production paradigms. The new information gained during JGOFS field programs should be used to help develop a new and expanded conceptual framework for nutrient dynamics in the sea. This ecumenical theory should also leave room for the additional discoveries that are likely to emerge. 다 


\section{Acknowledgements}

We thank the many technicians and scientists who have contributed to the success of the two U.S. JGOFS time-series programs and of elemental cycling research in other parts of JGOFS. We thank the National Science Foundation (NSF) and the other federal agencies for their financial support. We particularly thank NSF for support of the time-series stations and of nitrogen fixation research in the Biocomplexity Program. This is U.S. JGOFS Contribution Number 678.

\section{References}

Anderson, L. and J. Sarmiento, 1994: Redfield ratios of remineralization determined by nutrient data analysis. Global Biogeochem. Cycles, 8, 65-80.

Capone, D.G., 2001: Marine nitrogen fixation: What's the fuss? Current Opinions in Microbiology, 4, 341-348.

Capone, D.G., A. Subramaniam, J. Montoya, M. Voss, C. Humborg, A. Johansen, R. Siefert and E.J. Carpenter, 1998: An extensive bloom of the N2-fixing cyanobacterium, Trichodesmium erythraeum, in the central Arabian Sea. Mar. Ecol. Progress Series, 172, 281-292.

Deutsch, C., N. Gruber, R.M. Key, J.L. Sarmiento and A. Ganachaud, 2001: Denitrification and $\mathrm{N}_{2}$ fixation in the Pacific Ocean. Global Biogeochemical Cycles, $15,483-506$

Dugdale, R.C. and J.J. Goering, 1967: Uptake of new and regenerated forms of nitrogen in primary productivity. Limnol. and Oceanog., 12, 196-206.

Elser, J.J., D.R. Dodderfuhl, N.A. MacKay and J.H. Schampel, 1996: Organism size, life history, and $\mathrm{N}: \mathrm{P}$ stoichiometry. BioScience, 46, 674-684.

Eppley, R.W. and B.J. Peterson, 1979: Particulate organic matter flux and planktonic new production in the deep ocean. Nature, 282, 677-680.

Falkowski, P., 2000: Rationalizing elemental ratios in unicellular algae. Journal of Phycology, 36, 3-6.

Galloway, J.N., W.H. Schlesinger, H. Levy II, A. Michaels and J.L. Schnoor, 1995: Nitrogen fixation: Anthropogenic enhancement-environmental response. Global Biogeochem. Cycles, 9, 235-252.

Gruber, N. and J. Sarmiento, 1997: Global patterns of marine nitrogen fixation and denitrification. Global Biogeochem. Cycles, 11, 235-266.

Husar, R., J. Prospero and L. Stowe, 1997: Characterization of tropospheric aerosols over the oceans with the NOAA advanced very high resolution radiometer optical thickness operational product. Journal of Geophys. Res. Atmosph., 102, 16889-16909.

Karl, D., R. Letelier, L. Tupas, J. Dore, J. Christian and D. Hebel, 1997: The role of nitrogen fixation in biogeochemical cycling in the subtropical north Pacific ocean. Nature, 386, 533-538.

Karl, D.M., K.M. Bjorkman, J.E. Dore, L Fujieka, D.V. Hebel, T. Houlihan, R.M. Letelier and L.M Tupas,
2001: Ecological nitrogen-to-phosphorus stoichiometry at Station ALOHA. Deep-Sea Res. II, in press.

Martin, J.H., G.A. Knauer, D.M. Karl and W.W. Broenkow, 1987: VERTEX: carbon cycling in the northeast Pacific. Deep-Sea Res., 34, 267-85.

Michaels, A.F., N.R. Bates, K.O. Buesseler, C.A. Carlson and A.H. Knap, 1994: Carbon-cycle imbalances in the Sargasso sea. Nature, 372, 537-540.

Michaels, A.F., D. Olson, J.L. Sarmiento, J.W. Ammerman, K. Fanning, R. Jahnke, A.H. Knap, F. Lipschultz and J.M. Prospero, 1996: Inputs, losses and transformations of nitrogen and phosphorus in the pelagic north Atlantic ocean. Biogeochemistry, 35, 181-226.

Redfield, A.C., 1958: The biological control of chemical factors in the environment. Am. Sci., 46, 205-221.

Sambrotto, R.N., G. Savidge, C. Robinson, P. Boyd, T. Takahashi, D.M. Karl, C. Langdon, D. Chipman, J. Marra and L. Codispoti, 1993: Elevated consumption of carbon relative to nitrogen in the surface ocean. Nature, 36, 248-50.

Zehr, J.P., E.J. Carpenter and T.A. Villareal, 2000: New perspectives on nitrogen-fixing microorganisms in subtropical and tropical open oceans. Trends in Microbiology, 8, 68-73.

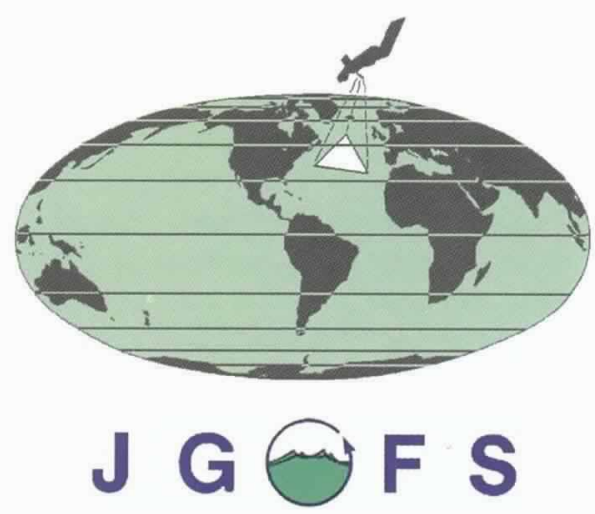

